\title{
GRAPHIC MODELING AND VISUAL IMPACT ON THE Structural Design of Packaging IN CAD APPLICATIONS
}

\author{
Pascu Nicoleta-Elisabeta ${ }^{\mathrm{a}}$, Dobrescu Tiberiu ${ }^{\mathrm{b}}$, Enciu George $^{\mathrm{b}}$, Jiga Gabriel $^{\mathrm{c}}$ \\ ${ }^{a}$ University Politehnica of Bucharest, Department of Engineering Graphics and Industrial Design, 313 Splaiul \\ Independenpei, 060042, Bucharest, Romania \\ ${ }^{b}$ University Politehnica of Bucharest, Department of Machine and Manufacturing Systems, 313 Splaiul Independenpei., \\ 060042, Bucharest, Romania \\ ${ }^{c}$ University Politehnica of Bucharest, Department of Material Resistance, 313 Splaiul Independenpei., 060042, \\ Bucharest, Romania
}

\begin{abstract}
This article aims to monitor and analyze trends in the conception domain and a structural design production of the packing for the art industry. It is a growing sector, where there are many innovations in designing solutions, materials and production technologies. The field of packaging presents an interest for seeing as one of its few sectors with an upward trend. When you opt for one product or another, our decision is based on several factors that have nothing to do with the actual quality of the product for which the structural design of a product can be tested as a concept by 3D modeling. In this article we argue the visual impact achieved by testing 3D structural design of the package before performing the prototype.
\end{abstract}

Keyword: 3D modeling; design; graphic; production
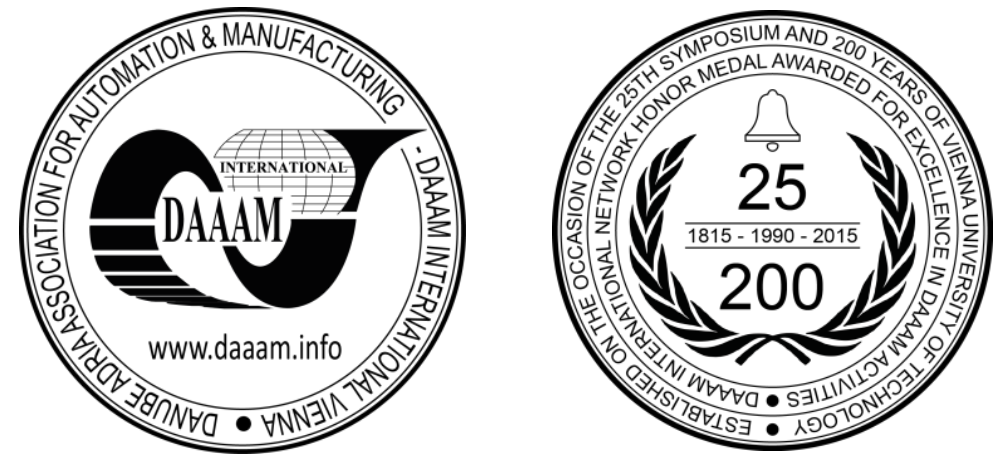

This Publication has to be referred as: Pascu, N[icoleta]; Dobrescu, T[iberiu]; Enciu, G[eorge] \& Jiga, G[abriel] (2016). Graphic Modeling and Visual Impact on the Structural Design of Packaging in CAD Applications, Proceedings of the 26th DAAAM International Symposium, pp.0265-0270, B. Katalinic (Ed.), Published by DAAAM International, ISBN 978-3-902734-07-5, ISSN 1726-9679, Vienna, Austria DOI:10.2507/26th.daaam.proceedings.036 


\section{Introduction}

The packaging design is the one which makes the difference between the different products on the shelf. The buyer of a product is often influenced by the structural design of the product. Recent studies show that packaging design of high quality attracts our attention persuades the customer to buy it.

Usually the packaging is an element made from different materials designed to protect, to carry, to sell or use a product. Packaging with its aims should combine art and technology. The design of the package should attract from the aesthetic and structural point of view and to highlight the qualities and benefits of the product. The design must adapt to all the needs of product with the remarkable features of colors, shapes, text and other particular elements. Through a quality design of the packaging, a product can reach among the consumer's favorite. The packaging design should take into consideration both the packaging graphics and packaging structural design. Structural design relates to the shape of the packing which is generally a less time-varying factor for a category of products. Few companies can afford a major change in structural design because it involves many convexes activities.

\section{The structural design}

Whatever the nature of the packaging, place or not, polyhedral packaging are considered as the most practical, which is most easily to stack on pallet or shelf space in retail without wasting space settlement.

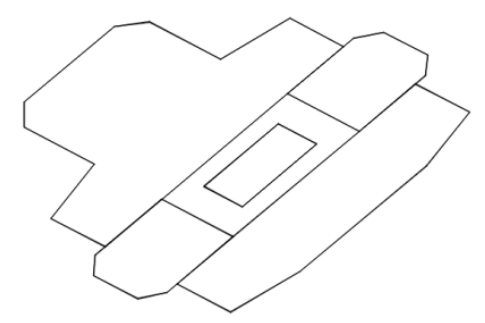

Fig. 1. Developed surface a polyhedral packing

Polyhedral packaging is found in a variety of shapes, sizes and materials, depending on the purpose of the pack and of the contents to be packaged. Packages polyhedral interior dimensions are listed and are presented in the following order: length $\mathrm{x}$ width $\mathrm{x}$ depth. To design polyhedral packaging is good to know the way of conducting, the composition of geometric shapes around the building a rectangular boxes, but also to imagine the possibility of folding when deployable packaging and the need for an intuitive understanding of complex polyhedrons, see Fig. 1.

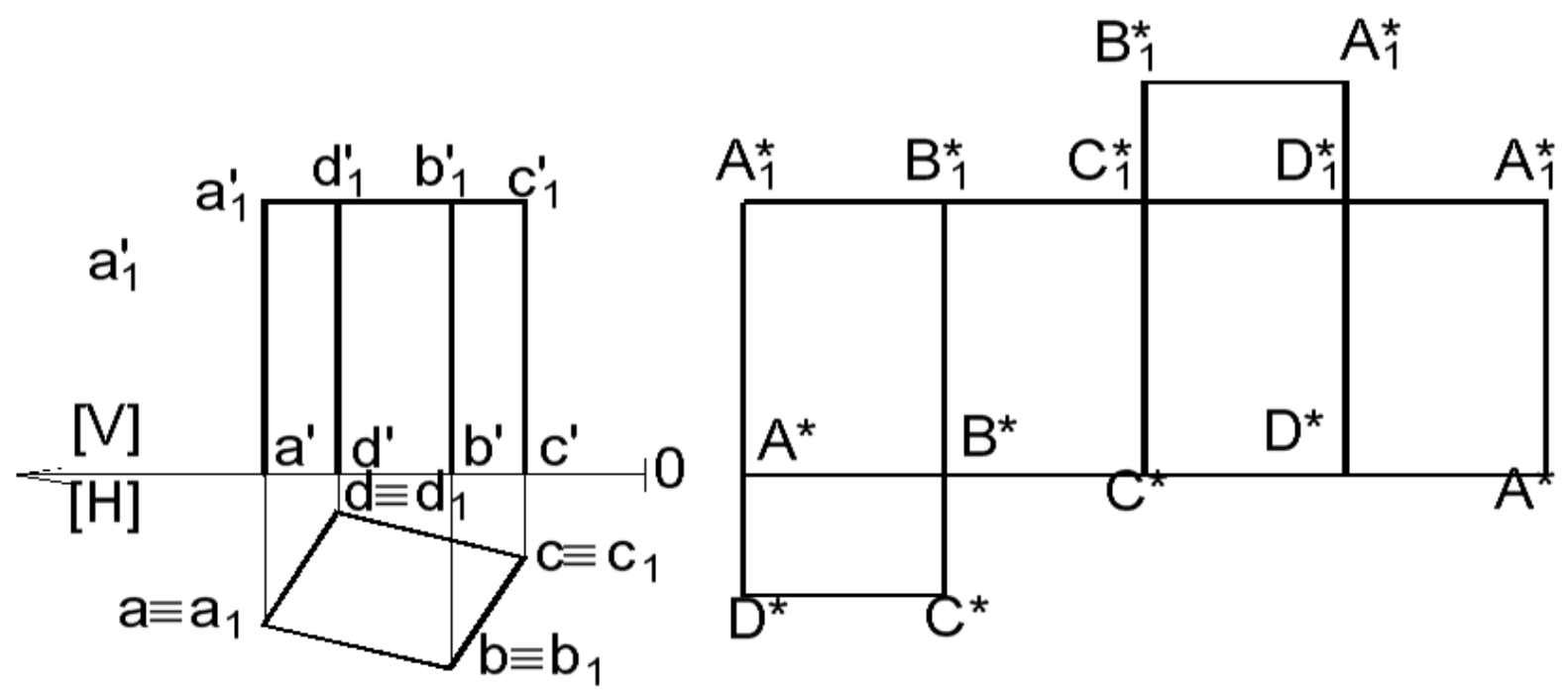

Fig. 2. Developed surface of a polyhedral packing having a rectangle base

Representing the flat faces of a polyhedron is made all in one deployment plan called polyhedral; see Fig. 2 and Fig. 3. Figure flat unfolded polyhedron obtained is called developed surface and is a flat polygonal figure. This figure contains flat polygonal shape of each face of the polyhedron real. 


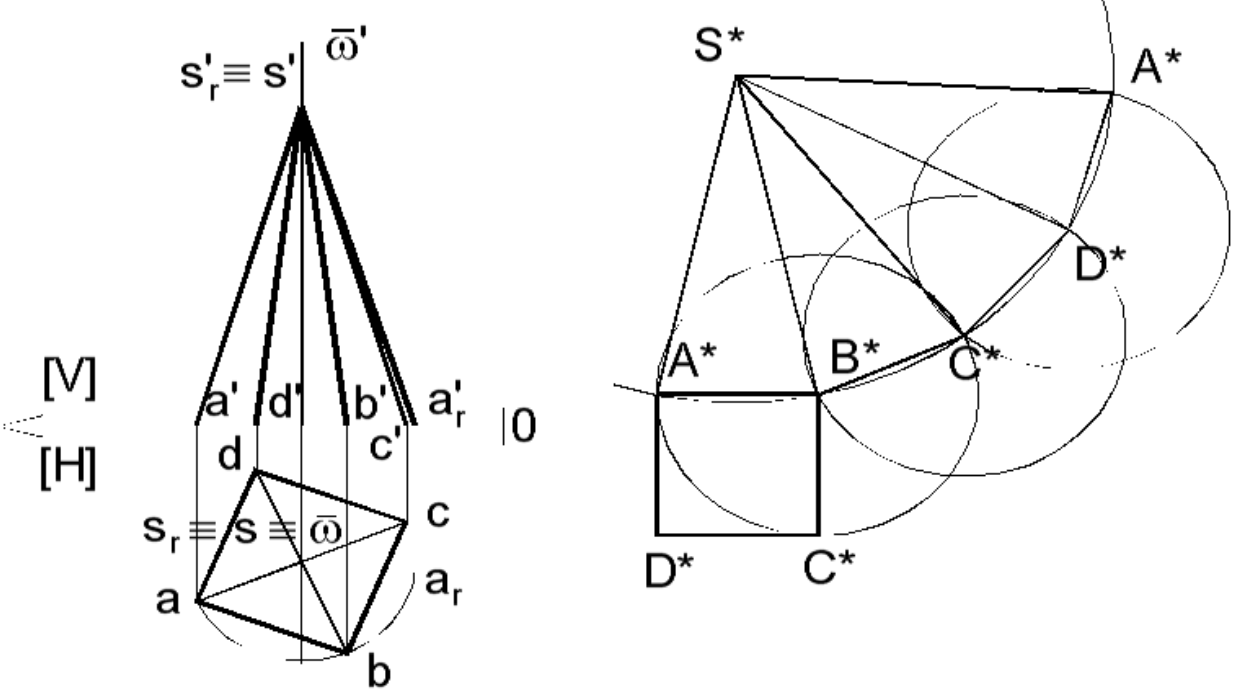

Fig. 3. Developed surface of a pyramid packing having a rectangular base

Packaging paper and cardboard cylindrical needs plastic film layers requires or metal foil. Cylindrical packages of cardboard are formed by closing the side wall (as a generator) and placing the ends in the shape of caps, see Fig. 4.Metal packaging (composite or not) have entered heads as a result of a processing process.

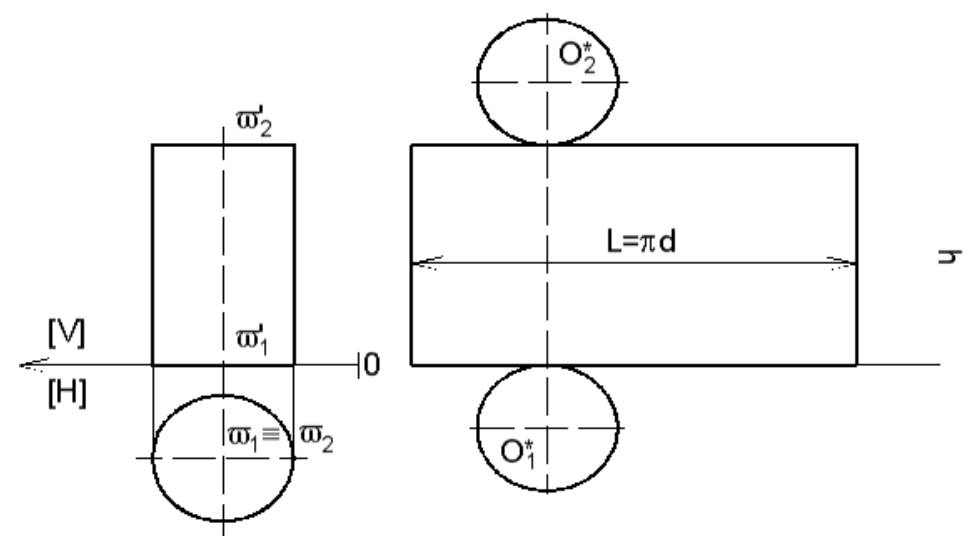

Fig. 4. Developed surface a cylindrical package

\section{Graphic modeling - virtual prototype}

The CAD programs use mathematic operations for creating shapes. The modeling begins by creating a basis part, Figure 1, [1]. After that, the model can be compacted by adding or removing other parts from the basis part. Initial stage of modeling objects have a gray matte, see Fig. 5 (a), by assigning a color to a surface can be differentiating components of a whole, see Fig. 5 (b)[2]. But this is not sufficient for a realistic picture accomplishment. Achieving realistic surfaces is more than a color application. A texture is an image see Fig. 6, often closely linked to material object. However, you can map a texture to the object.

a

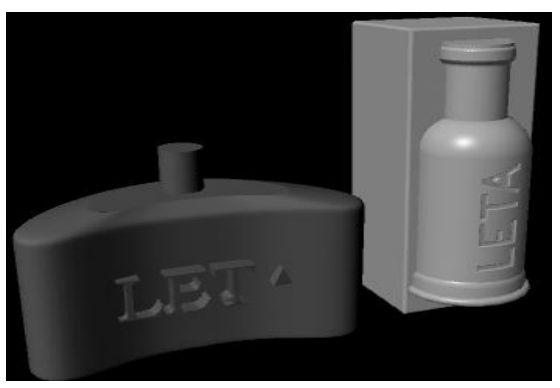

$\mathrm{b}$

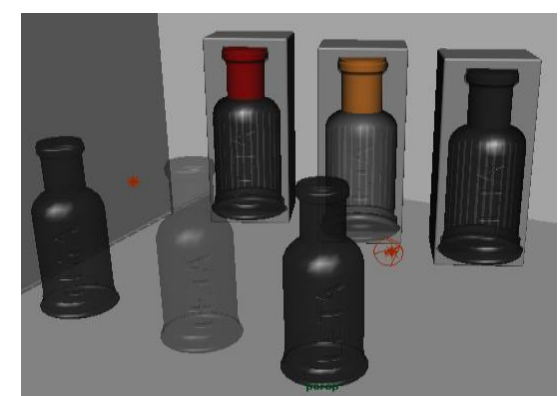

Fig. 5. (a) Objects have a gray matte texture; (b)assigning a color to a surface 
So in a scene multiple objects must be present to talk about reflection, an object to have something to reflect, see Fig. 6 . Refraction is the change in angle of light rays when they enter a denser medium.

CAD programs allow setting an index of refraction, which can control the angle of the light deviates when joining surface of contact between two different environments [2,3].

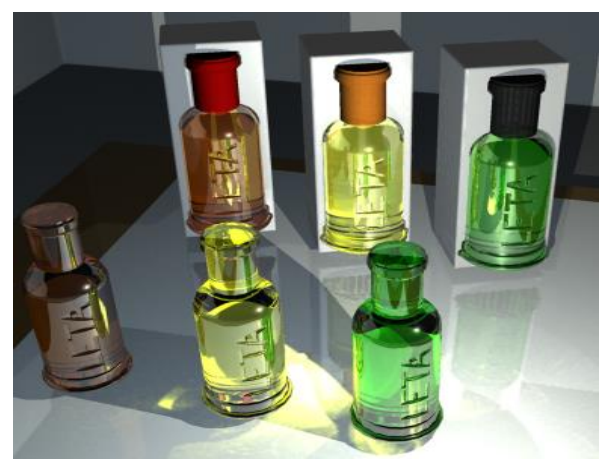

Fig. 6. Reflection

The study of the light in a 3D scene depends on certain factors, such as: direction, angle of incidence, reflection and refraction, see Fig. 7. Light sources in a scene create shadows. There are two types of light sources: natural (overall sources in 3D modeling) and artificial (punctual sources in 3D modeling). Refraction is a change in the angle of light rays when they reach into a dense medium, as glass or a liquid, see Fig. 7.

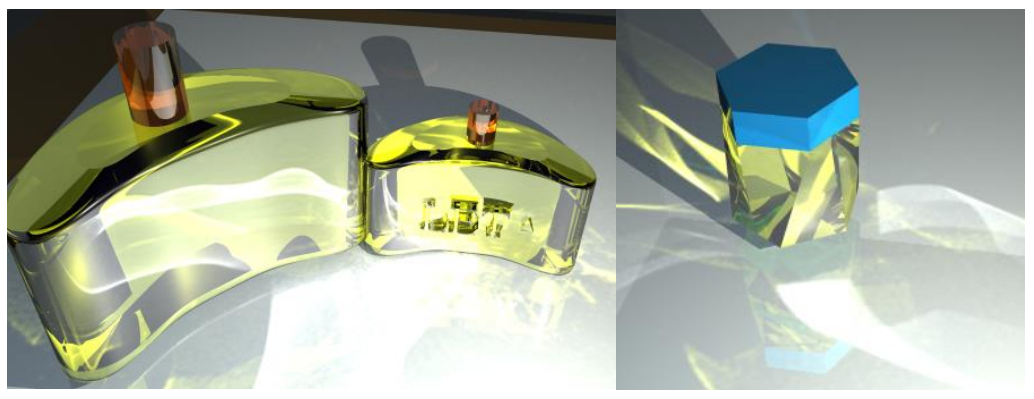

Fig. 7. Reflection and refraction in a simple scene

\section{Applying the "focus group" for analysis 3D modeling CAD package}

Glass packaging (bottles and jars) is customized in terms of design through form, color and label them. It is known that in Romania and not only there are a lot of brands that use bottles and glasses customized to draw attention to their brand. For example, the product is packaged in a cardboard box containing a glass engraved with that brand. The purpose of this chapter is to extend its geometric shapes in designing industrial products.

Starting with basic geometric shapes (cylinder, cone, prism, etc.) through geometric transformation operations (rotations, translations, etc.) provided new complex configurations with different functional properties and different geometric respecting the original forms see Fig. 8 [4, 5].

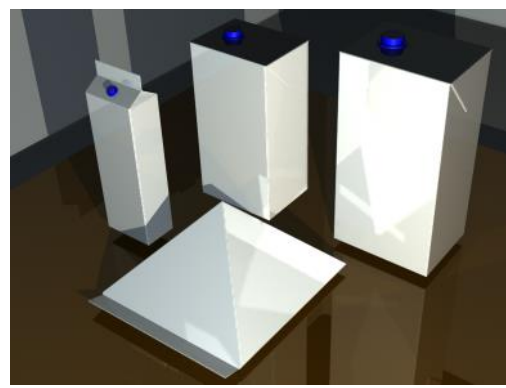

Fig. 8. Simple geometric shapes

All those participating in the discussion remain anonymous, therefore we shall call subjective. It invites a lot during a debate consisting of 8 people who do not know each other and are not in a relationship of subordination. There will be ten such debates. It announces the purpose of this discussion and rules of debate: 
- Want to find potential buyers opinion about the new packaging;

- This discussion will long thirty minutes;

- The presentations are involved in the discussion with the purpose of knowing each other;

- The expression is made in a free way;

- We are interested in your opinion about the new packaging;

- When something unusual occurs with any questions you may move in that direction;

- There are provided several pictures and then more questions are addressed for the subjects regarding packing.

a

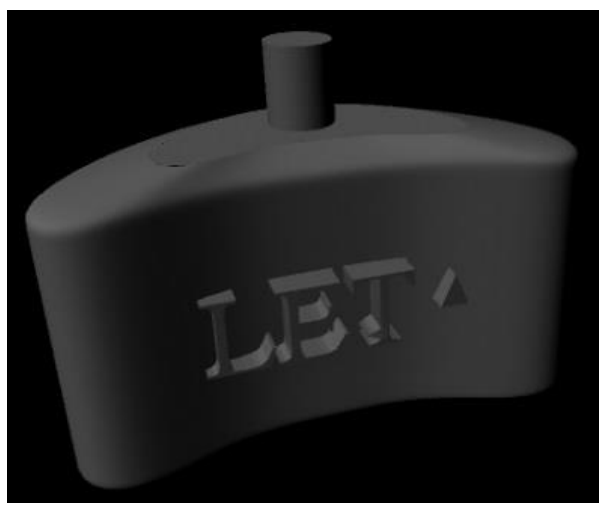

b

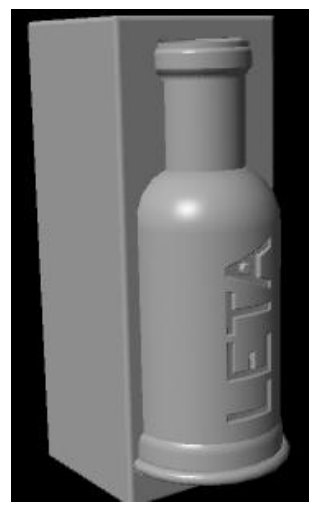

$\mathrm{C}$

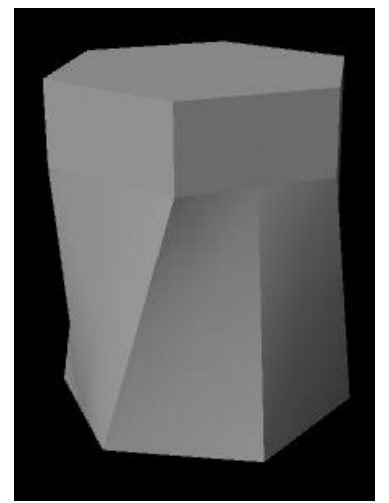

Fig. 9. (a) Product A; (b) Product B; (c) Product C

The packaging that needs to be tested among the target group chosen is the product A. After achieving this focus group the results obtained will be used to develop questionnaires. This tool will be used in a subsequent step in quantitative research [6]. This qualitative method has been chosen to identify all the nuances of the phenomenon studied and to identify the range of views of interested clients before achieving eventual prototype. Some of these questions are presented in table1.

\begin{tabular}{|c|c|}
\hline Question & Weights \\
\hline $\begin{array}{l}\text { What are the criteria for choosing a product? } \\
\text { a) quality, utility and design } \\
\text { b) brand, packaging and quality } \\
\text { c) promotion, attractive design and low price } \\
\text { d) innovative design, quality and average price }\end{array}$ & $\begin{array}{l}\text { a) } 14 \% \\
\text { b) } 12 \% \\
\text { c) } 60 \% \\
\text { d) } 14 \%\end{array}$ \\
\hline $\begin{array}{l}\text { Which of the packing's from this picture do you } \\
\text { consider the most attractive } \\
\text { a) Product A } \\
\text { b) Product B } \\
\text { c) Product C }\end{array}$ & $\begin{array}{l}\text { a) } 40 \% \\
\text { b) } 60 \% \\
\text { c) } 0 \%\end{array}$ \\
\hline $\begin{array}{l}\text { When you choose a product what is more important } \\
\text { for you? } \\
\text { a) Price } \\
\text { b) Color } \\
\text { c) Brand } \\
\text { d) Design } \\
\text { e) Quality }\end{array}$ & $\begin{array}{l}\text { a) } 50 \% \\
\text { b) } 10 \% \\
\text { c) } 15 \% \\
\text { d) } 5 \% \\
\text { e) } 20 \%\end{array}$ \\
\hline $\begin{array}{l}\text { For a more attractive package will you be willing to } \\
\text { pay more? } \\
\text { a) Not } \\
\text { b) Maybe } \\
\text { c) Yes }\end{array}$ & $\begin{array}{l}\text { a) } 64 \% \\
\text { b) } 25 \% \\
\text { c) } 11 \%\end{array}$ \\
\hline $\begin{array}{l}\text { What drinks will you buy if they have been packed } \\
\text { under this form } \\
\text { a) Perfume } \\
\text { b) Beer } \\
\text { c) Coffee } \\
\text { d) Tea } \\
\text { e) Whiskey }\end{array}$ & $\begin{array}{l}\text { a) } 55 \% \\
\text { b) } 30 \% \\
\text { c) } 5 \% \\
\text { d) } 5 \% \\
\text { e) } 5 \%\end{array}$ \\
\hline
\end{tabular}

Table 1. Questions addressed subjects 


\section{Conclusions}

Following these responses it can make a statistical analysis and can take into account all the information to the final design, price and preferred content, the package passed. As a result of this qualitative study through the images will be compiled in a final stage of a questionnaire for the quantitative analysis. The packaging that needs to be promoted, should meet the following characteristics to be successful: quality is paramount; visually appealing design pack-image matters a lot in the subjects' preferences. Special attention should be paid to this aspect compared to the cost of production (almost non-existent differences between colors packaging).

\section{References}

[1] N. E. Pascu, (2009), "3D Modelling of polyhedral with regular faces and other families of polyedra”, The 3nd International conference on engineering graphics and design ICEGD, Acta Tehnica Napocensis, Series: Applied Mathematics and Mechanics 52, Vol. Ia,12-13 June 2009, ISSN 1221-5872, Ed. Technical University of ClujNapoca, pp. 323-326.

[2] Pascu Nicoleta Elisabeta, Dobrescu Tiberiu Gabriel, Opran Constantin, Enciu George, (2014) Realistic scenes in cad application, Journal Procedia Engineering, Vol. 69, Published by Elsevier Ltd., ISSN 1877-7058, pp. 304 309 ,.

[3] Adir, V., Adir, G., Pascu, N., E., (2013) "How to design a logo", 2nd World Conference on Design, Arts \& Education (DAE-2013), 09-12 May 2013, Bucharest, Romania, Publisher ELSEVIER SCIENCE BV, SARA BURGERHARTSTRAAT 25, AMSTERDAM, NETHERLANDS, (2013), pp 140-144.

[4] Popa Cicerone Laurentiu, Cotet Costel Emil, , Ionita, Valentin, Gavrila Stefan, (2015), Modeling processing cell architecture by material flow simulation, Procedia Engineering Volume 100, 2015, 25th DAAAM International Symposium on Intelligent Manufacturing and Automation, pp 334-339.

[5] Catalin Gheorghe Amza, , Dumitru Titi Cicic, (2015), Industrial Image Processing Using Fuzzy-logic, Procedia Engineering, Volume 100, 2015, 25th DAAAM International Symposium on Intelligent Manufacturing and Automation, pp. 492-498.

[6] Peter Poór, Nikol Kuchtová, Michal Šimon, (2013), Machinery Maintenance as Part of Facility Management, Procedia Engineering, Volume 100, 2013, 25th DAAAM International Symposium on Intelligent Manufacturing and Automation, pp. 1276-1280. 